\title{
Cryptotanshinone inhibits lung cancer invasion via microRNA-133a/matrix metalloproteinase 14 regulation
}

\author{
HUIJUAN WANG ${ }^{1}$, YANSHAN ZHANG ${ }^{2}$, YINGGUO ZHANG ${ }^{2}$, WENLING LIU ${ }^{2}$ and JIHONG WANG ${ }^{2}$ \\ Departments of ${ }^{1}$ Tumor Chemotherapy and ${ }^{2}$ Thoracic Surgery, \\ Tumor Hospital of Wuwei, Wuwei, Gansu 733000, P.R. China
}

Received April 10, 2018; Accepted April 4, 2019

DOI: $10.3892 / \mathrm{ol} .2019 .10580$

\begin{abstract}
Cryptotanshinone inhibits the proliferative and colony formation abilities of human non-small cell lung cancer cells (NSCLCs). The present study reported that signal transducer and activator of transcription 3 is not the only target of cryptotanshinone during the inhibition of human NSCLCs. It was identified that cryptotanshinone upregulates the expression levels of microRNA (miR)-30d-5p, miR-126-3p, miR-133a, miR-338-3p and miR-451a, and downregulates miR-21-5p, miR-96-5p, miR-182-5p and miR-205-5p. Among these, miR-133a was the most significantly upregulated. miR-133a targets and downregulates the expression of matrix metalloproteinase (MMP)14; however, MMP15, MMP16 and MMP24 were determined to be unaffected. This process was identified to be independent of tissue inhibitor of metalloproteinases 2. Cryptotanshinone also suppresses the invasion of human NSCLCs, which may be due to the inhibited expression of MMP14. In conclusion, cryptotanshinone may serve as a potential therapeutic agent in the treatment of lung cancer.
\end{abstract}

\section{Introduction}

Lung cancer is a malignant lung tumor characterized by uncontrolled lung cell proliferation (1). It is the most commonly diagnosed cancer and the leading cause of cancer-associated mortality (2). Therefore, discovering an effective drug with low toxicity for the treatment of lung cancer is necessary. Human non-small cell lung cancer (NSCLC) cell line, including human A549 lung adenocarcinoma epithelial cell line is widely used as a lung cancer study model (3).

Cryptotanshinone is a natural quinoid diterpene isolated from the roots of a traditional herb Salvia miltiorrhiza, which is considered a potent anticancer agent with anticancer

Correspondence to: Dr Yanshan Zhang, Department of Thoracic Surgery, Tumor Hospital of Wuwei, 31 Health St, Haizang Rd, Wuwei, Gansu 733000, P.R. China

E-mail: zhang-yanshan@163.com

Key words: cryptotanshinone, lung cancer, microRNA-133a, matrix metalloproteinase 14 , cancer cell invasion activities (4). In our previous study, it was reported that cryptotanshinone could inhibit the growth of human lung cancer cells and induce apoptosis (5). Signal transducer and activator of transcription 3 (STAT3) is a key transcription activator for cancer cell proliferation. As a STAT3 inhibitor, cryptotanshinone responds to STAT3-induced cytokines and growth factors $(6,7)$; however, to the best of our knowledge, whether STAT3 is the only target of cryptotanshinone remains unclear.

MicroRNAs (miRNAs/miRs) are small non-coding RNA molecules that are 22 nucleotides long and function in RNA silencing and post-transcriptional gene regulation (8). miRNAs serve an important role in lung cancer $(9,10)$. The principal miRNAs involved in lung cancer are members of the let-7 family, including miR-34, miR133, miR-17 and miR-124 (11-13). The present study first investigated if STAT3 was the only target of cryptotanshinone in lung cancer cells. It was identified that even without regulation of STAT3 signaling, cryptotanshinone could inhibit the proliferation and colony formation of lung cancer cells. Based on this result, the effects of cryptotanshinone on miRNAs were investigated using reverse transcription-quantitative polymerase chain reaction (RT-qPCR). In addition, the expression levels of matrix metalloproteinases (MMPs) were studied. Finally, the effects of cryptotanshinone on lung cancer cell invasion were also detected. In summary, the findings of the present study provides further insight into the anticancer effects of cryptotanshinone.

\section{Materials and methods}

Chemical treatments and cytotoxic effects assessment. The human A549 lung adenocarcinoma epithelial cell line, one of the NSCLC cell lines, is the most common human lung cancer cell line used for studies regarding lung cancer $(1,3)$. Cell culture was performed following our previous method (5). Briefly, A549 was propagated in RPMI-1640 cell culture medium (Gibco; Thermo Fisher Scientific, Inc.) with L-glutamine, $100 \mathrm{U} / \mathrm{ml}$ penicillin, $100 \mu \mathrm{g} / \mathrm{ml}$ streptomycin, and 10\% (v/v) fetal bovine serum (FBS; Gibco; Thermo Fisher Scientific, Inc.) at $37^{\circ} \mathrm{C}$ with $5 \% \mathrm{CO}_{2} . \mathrm{A} 549$ cells $\left(5 \times 10^{3}\right.$ cells/well $)$ were seeded in a 96-well plate (Corning, Inc.). Cells were treated with cryptotanshinone (LKT Laboratories, Inc.) dissolved in $0.1 \%$ dissolved in dimethyl sulfoxide (DMSO), defined as the CT group, at a final concentration of $20 \mu \mathrm{M}$ (4) for 24 , 
36 and $48 \mathrm{~h}$. The control group was treated with $0.1 \%$ DMSO, defined as the NC group. Colivelin, a STAT3 activator, was purchased from Santa Cruz Biotechnology, Inc. (Dallas, TX, USA). The final concentration of colivelin (dissolved in DMSO) was $100 \mu \mathrm{M}$ and cells treated, at $37^{\circ} \mathrm{C}$, with colivelin were termed the $\mathrm{CV}$ group, while cells treated with both $20 \mu \mathrm{M}$ cryptotanshinone and $100 \mu \mathrm{M}$ colivelin were termed the $\mathrm{CT}+\mathrm{CV}$ group. Activity of STAT3 in the NC, CT, CV and $\mathrm{CT}+\mathrm{CV}$ groups was detected by enzyme-linked immunosorbent assay (ELISA) using a STAT3 (Phospho) [pY705] Multispecies ELISA kit (cat. no. KHO0481; Thermo Fisher Scientific Inc.), according to the manufacturer's protocol. Following treatment at $37^{\circ} \mathrm{C}$ for 24,48 and $72 \mathrm{~h}$ the cytotoxic effects of cryptotanshinone and colivelin in the $\mathrm{NC}$, $\mathrm{CT}$ and $\mathrm{CT}+\mathrm{CV}$ groups were detected using an MTT assay. The optical density (OD) was measured using iMark ${ }^{\mathrm{TM}}$ Microplate Absorbance Reader (Bio-Rad Laboratories, Inc.) at $450 \mathrm{~nm}$, representing the activity of STAT3. Colony formation was detected as described previously (4). Briefly, A549 cells $(n=250)$ were seeded in 6 -well Corning ${ }^{\mathrm{TM}}$ Costar $^{\mathrm{TM}}$ Flat Bottom Cell Culture Plates ( $D=35 \mathrm{~mm}$, Corning, Inc.) and allowed to attach overnight prior to treatment with $20 \mu \mathrm{M}$ cryptotanshinone dissolved in DMSO or $0.1 \%$ DMSO (control), and were incubated for 10 days. The colonies were stained with $0.5 \%$ crystal violet in methanol/acetic acid (3:1) and those composed of $>50$ cells were counted. Experiments were performed three times in duplicate.

RT-qPCR and western blot analysis. A549 cells were treated with $20 \mu \mathrm{M}$ cryptotanshinone or with $0.1 \%$ DMSO at $37^{\circ} \mathrm{C}$ for $6 \mathrm{~h}$, followed by miRNA detection. miRNA was isolated from the $\mathrm{NC}, \mathrm{CT}$ and $\mathrm{CT}+\mathrm{CV}$ groups using an mirVana ${ }^{\mathrm{TM}}$ miRNA Isolation kit with phenol (Thermo Fisher Scientific Inc.) and converted to complementary DNA using a TaqMan ${ }^{\mathrm{TM}}$ MicroRNA Reverse Transcription kit (cat. no. 4366597; Thermo Fisher Scientific Inc.). miRNA analysis was conducted using a miScript miRNA PCR array (cat. no. MIHS-114Z; Qiagen $\mathrm{GmbH}$, Hilden, Germany) following its instruction. RT-qPCR was performed on Applied Biosystems ${ }^{\mathrm{TM}} 7500$ Fast Real-time PCR. PCR thermocycling conditions were as follows: $50^{\circ} \mathrm{C} 2$ $\min ; 95^{\circ} \mathrm{C} 2 \mathrm{~min} ; 95^{\circ} \mathrm{C} 15 \mathrm{sec} ; 60^{\circ} \mathrm{C} 1 \mathrm{~min}, 40$ cycles. Melt curve stage: $95^{\circ} \mathrm{C} 15 \mathrm{sec} ; 60^{\circ} \mathrm{C} 1 \mathrm{~min} ; 95^{\circ} \mathrm{C} 15 \mathrm{sec}$.

Western blot analysis. For western blot analysis, $20 \mu \mathrm{g}$ protein was extracted using Cell lysis buffer for Western and IP (cat no. P0013; Beyotime Institute of Biotechnology), determined using BCA kits (cat no. P0012; Beyotime Institute of Biotechnology) and boiled with NuPAGE ${ }^{\mathrm{TM}}$ LDS Sample Buffer (4X) (Invitrogen; Thermo Fisher Scientific, Inc.; cat no. NP0007) at $100^{\circ} \mathrm{C}$ for 5 min prior to injection in a $12.5 \%$ SDS-PAGE. Following electrophoresis and transfer, the polyvinylidene fluoride (PVDF) membrane (Invitrogen; Thermo Fisher Scientific Inc.) was blocked in 5\% non-fat milk for $1 \mathrm{~h}$, incubated overnight at $4^{\circ} \mathrm{C}$ with primary antibodies as follows: MMP14 (dilution, 1:800; cat. no. ab53712), MMP15 (dilution, 1:500; cat. no. ab15475), MMP16 (dilution, 1:800; cat. no. ab53145), MMP24 (dilution, 1:400; cat. no. ab135564) and tissue inhibitor of metalloproteinases 2 (TIMP2; dilution, 1:1,000; cat. no. ab199707). All primary antibodies were purchased from Abcam (Cambridge, UK) and incubated subsequently with secondary antibody Goat Anti-Rabbit IgG H\&L (HRP) (dilution, 1:5,000; cat. no. ab205718) for $1 \mathrm{~h}$ at room temperature, washed and exposed. GAPDH (dilution, 1:10,000; cat. no. ab181602) was used as loading control. Membranes were incubated in Pierce ${ }^{\mathrm{TM}}$ ECL Western Blotting Substrate for $1 \mathrm{~min}$ at room temperature (solution A:solution B=1:1; Thermo Scientific Inc.; cat. no. 32106) and images were captured using LAS-3000 Imaging System (Fuji, Japan). The expression value (target protein/ GAPDH) in the control group was set as 1 , while the relative values for the cryptotanshinone group were calculated in association with the control group using ImageJ (National Institutes of Health, Bethesda). All experiments were performed three times with a duplicate each time. Data are compared between the $\mathrm{NC}$ and $\mathrm{CT}$ groups.

Cancer cell invasion assay. A cancer cell invasion assay was conducted using a Corning ${ }^{\circledR}$ BioCoat $^{\mathrm{TM}}$ Matrigel ${ }^{\circledR}$ Invasion Chamber (Corning Inc., Corning, NY, USA), according to the manufacturer's protocol at $37^{\circ} \mathrm{C}$. The culture medium was Gibco DMEM, High Glucose, Pyruvate (cat. no. 11-995-040; Gibco; Thermo Fisher Scientific Inc.) with 10\% FBS (cat. no. 10437010; Gibco; Thermo Fisher Scientific Inc.) for lower chamber and 0.1\% BSA (Gibco; Thermo Fisher Scientific, Inc.; cat. no. 11021029) for upper chamber. Briefly, the medium was subsequently rehydrated for $2 \mathrm{~h}$, and fresh culture medium containing $5 \times 10^{4} \mathrm{~A} 549$ cells $/ \mathrm{ml}$ was plated in the upper 24-well chambers with $0.1 \%$ DMSO (NC group) or $20 \mu \mathrm{M}$ cryptotanshinone (CT group). The cells were then incubated for $36 \mathrm{~h}$ at $37^{\circ} \mathrm{C}$ with $5 \% \mathrm{CO}_{2}$. Subsequently, the inserts were transferred to $100 \%$ methanol for $2 \mathrm{~min}$ and then to $1 \%$ Toluidine Blue in $1 \%$ borax for $2 \mathrm{~min}$ at room temperature. Three fields/view were selected randomly and then analyzed. Images were obtained under Nikon TE2000 light microscope (magnification, x100; Nikon Corporation, Japan).

Statistical analysis. Data are presented as the mean \pm standard deviation. A Mann Whitney $U$ test was used for comparisons between two groups. One-way analysis of variance followed by a post-hoc Tukey's test was used to compare multiple groups. All statistical analysis was performed using SPSS 19.0 (IBM Corp., Armonk, NY, USA). P $<0.05$ was considered to indicate a statistically significant difference.

\section{Results}

Inhibition of STAT3 activity. As demonstrated in Fig. 1A, the OD value representing the STAT3 activity, was significantly decreased following treatment with cryptotanshinone, while treatment with colivelin significantly increased the OD 450 value compared with the control group. In the combined treatment group, the OD value was significantly increased compared with NC and CT groups, but remained lower than the $\mathrm{CV}$ group. These results indicated that cryptotanshinone could serve as a STAT3 inhibitor and colivelin as a STAT3 activator.

Cytotoxic effects of cryptotanshinone and colivelin. As demonstrated in Fig. 1B, following treatment with cryptotanshinone for 24, 48 and $72 \mathrm{~h}$ the cellular proliferation of A549 cells 
A

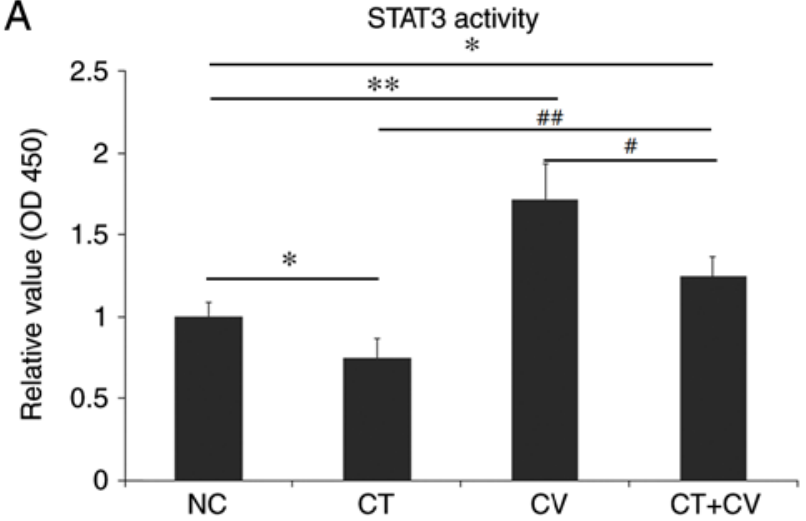

B

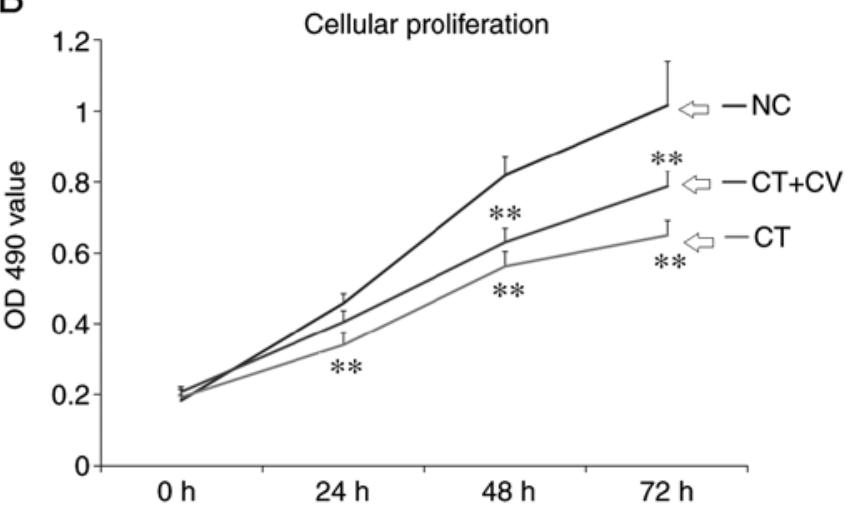

Figure 1. STAT3 activity and cellular proliferation of A549 cells. (A) OD 450 values of STAT3 activity in the CT, CV, CT+CV and NC groups. STAT3 activity significantly decreased following treatment with cryptotanshinone and significantly increased following treatment with colivelin. The OD 450 value was higher in the combined treatment group compared with the $\mathrm{NC}$ and $\mathrm{CT}$ groups. ${ }^{*} \mathrm{P}<0.05,{ }^{* *} \mathrm{P}<0.01$ vs. NC group. ${ }^{*} \mathrm{P}<0.05,{ }^{\# \#} \mathrm{P}<0.01$ vs. CT+CV combined treatment group. (B) The OD 450 values represent the cellular proliferation rate of A549 cells in the CT, CT+CV and NC groups. Following treatment with cryptotanshinone, the cellular proliferation rate was significantly decreased compared with the NC group. Combined treatment with colivelin partly reduced the cytotoxic effects of cryptotanshinone. Data are presented as the mean \pm standard deviation. ${ }^{* *} \mathrm{P}<0.01$ vs. NC group. STAT3, signal transducer and activator of transcription 3; OD, optical density; CT, cryptotanshinone-treated; CV, colivelin-treated; CT+CV, cryptotanshinone and colivelin-treated; NC, negative control.
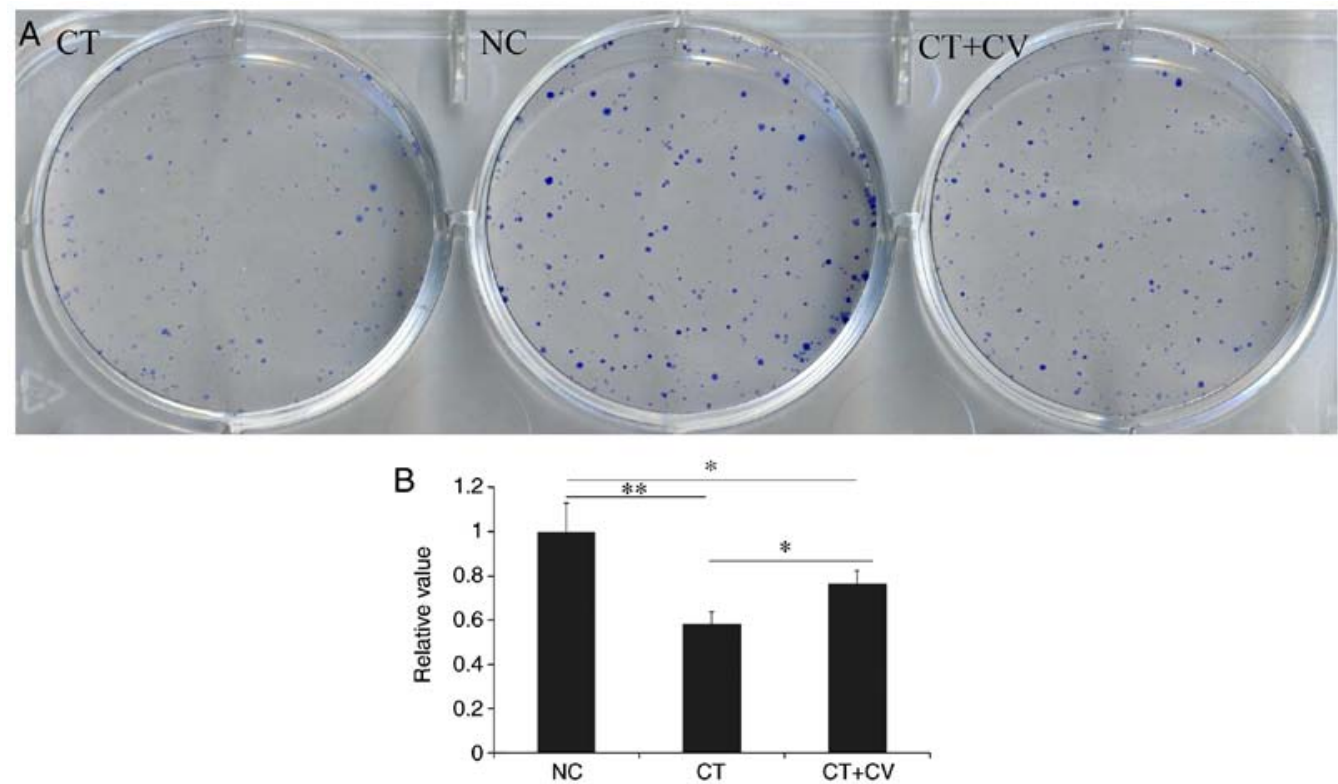

Figure 2. (A) Tumor colony formation in the $\mathrm{CT}, \mathrm{NC}$ and $\mathrm{CT}+\mathrm{CV}$ group (diameter $=35 \mathrm{~mm}$ for culture dish). Compared with the $\mathrm{NC}$ group, the number and size of tumor colonies were decreased in the CT group. Combined treatment markedly increased the number and size of colonies. (B) Data analysis for tumor colony formation in the $\mathrm{CT}, \mathrm{NC}$ and $\mathrm{CT}+\mathrm{CV}$ groups. " $\mathrm{P}<0.05,{ }^{* *} \mathrm{P}<0.01$. CT, cryptotanshinone-treated; $\mathrm{CT}+\mathrm{CV}$, cryptotanshinone and colivelin-treated; $\mathrm{NC}$, negative control.

significantly decreased compared with the control. Combined treatment with the STAT3 activator colivelin, was revealed to reduce the cytotoxic effects of cryptotanshinone, however, the cellular proliferation rate remained lower compared with control group. As demonstrated in Fig. 2, compared with NC group, the number and size of colony formation was significantly decreased in the CT group. Combined treatment with the STAT3 activator colivelin, significantly increased the number and size of colony formation compared with the CT group; however, colony formation was notably reduced compared with the control group. These results indicate that, in addition to the STAT3 pathway, there may be another mechanism involved in the cytotoxic effects of cryptotanshinone on A549 cells. The colony number in $\mathrm{NC}$ group was set as 1 and relative values in other groups were calculated by comparison. Data are presented in Fig. 2B.

Upregulation of miR-133a following treatment with cryptotanshinone. As demonstrated in Fig. 3, the following miRNAs were identified to be upregulated in A549 cells following treatment with cryptotanshinone: miR-30d-5p, miR-126-3p, miR-133a, miR-338-3p and miR-451a. By contrast, the following miRNAs were revealed to be downregulated following treatment with cryptotanshinone: miR-21-5p, miR-96-5p, miR-182-5p and miR-205-5p. These miRNAs target anti-apoptotic or pro-anti-apoptotic genes (14). Among 


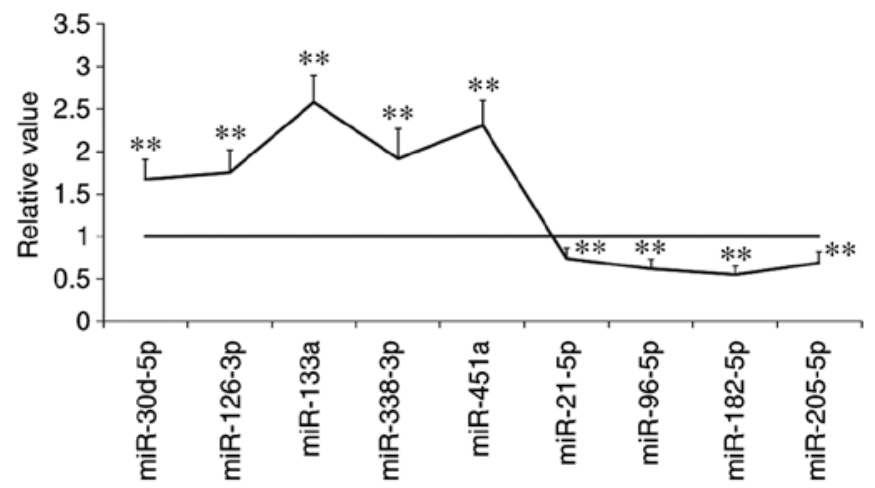

Figure 3. The expression levels of numerous miRNAs were either upregulated or downregulated following treatment with cryptotanshinone. Data are presented as the mean \pm standard deviation. ${ }^{* *} \mathrm{P}<0.01$ vs. relative expression set to 1 . miRNA/miR, microRNA.

A

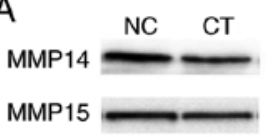

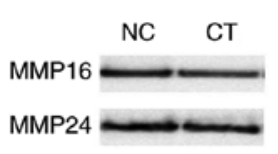

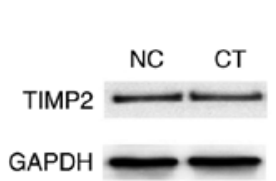

B

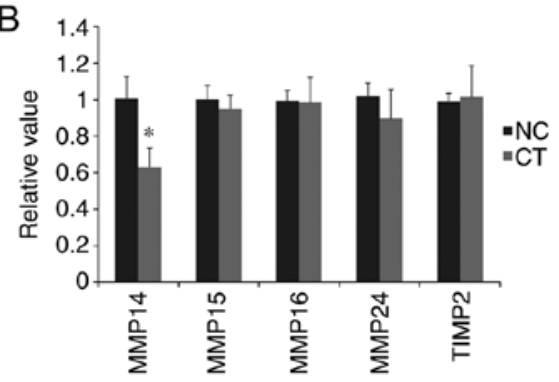

Figure 4. Western blot analysis of protein expression levels. (A) Expression levels of MMP14, MMP15, MMP16, MMP24 and TIMP2 in the CT and NC groups. (B) Following treatment with cryptotanshinone, the expression level of MMP14 was significantly downregulated, while no significant differences were identified for the other proteins. GAPDH was used as control. Data are presented as the mean \pm standard deviation. ${ }^{*}<<0.05$ vs. NC group. MMP, matrix metalloproteinase; TIMP2, tissue inhibitor of metalloproteinases 2; CT, cryptotanshinone-treated; NC, negative control.

A

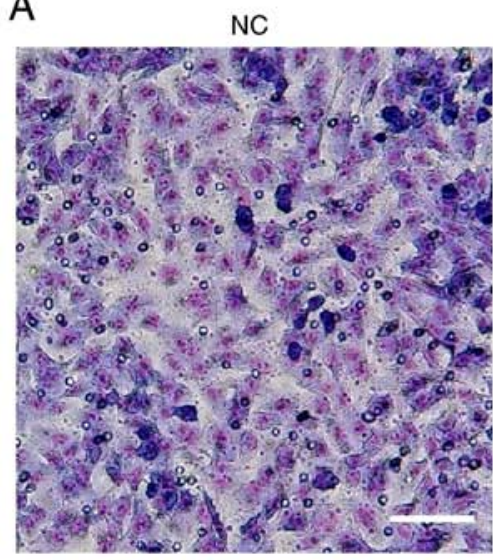

CT

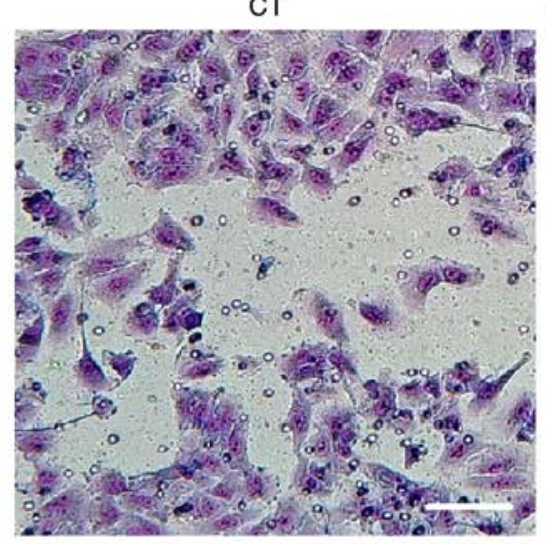

B

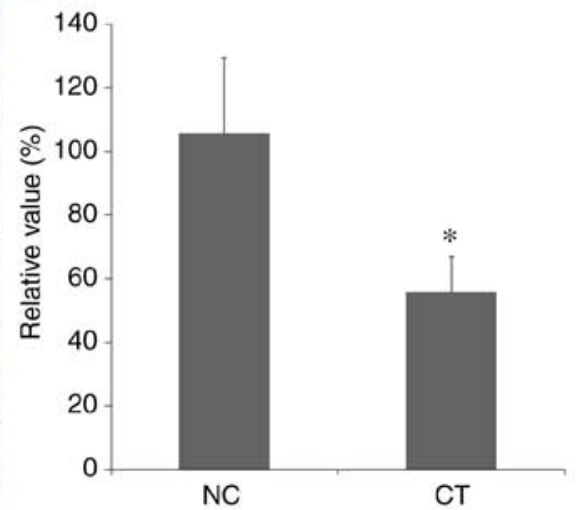

Figure 5. Invasion assay. (A) Cancer cell invasion was investigated using a Corning ${ }^{\circledR}$ BioCoat $^{\mathrm{TM}}$ Matrigel $^{\circledR}$ Invasion Chamber. Magnification, $\mathrm{x} 100$. Scale bar $=50 \mu \mathrm{m}$. (B) The number of invasive A549 cells was significantly reduced following treatment with cryptotanshinone compared with the control. Data are presented as the mean \pm standard deviation. ${ }^{\mathrm{P}}<0.05$ vs. NC group. CT, cryptotanshinone-treated; NC, negative control.

the microRNAs identified, miR-133a was the most significantly upregulated.

Downregulation of MMP14 following treatment with cryptotanshinone. As demonstrated in Fig. 4, following treatment with cryptotanshinone, the expression levels of MMP14 were significantly downregulated compared with the control. By contrast, no significant differences were identified in the expression levels of MMP15, MMP16 and MMP24. This suggested the potential involvement of MMP14 in cryptotanshinone-mediated cellular apoptosis. In addition, no significant difference was revealed in the expression of TIMP2 following treatment with cryptotanshinone. Based on these findings, MMP14 may be considered as a potential target of miR-133a, which acts independently of TIMP2 regulation.

Inhibition of cancer cell invasion. As demonstrated in Fig. 5, the number of invasive A549 cells was significantly reduced 
following treatment with cryptotanshinone. This indicated that the invasive capability of human lung adenocarcinoma epithelial A549 cells was significantly inhibited following treatment with cryptotanshinone.

\section{Discussion}

As a transcription activator that is translocated to the cell nucleus, STAT3 is activated following phosphorylation by receptor-associated Janus kinases (15). STAT3 serves a key role in the growth and apoptosis of cancer cells, including lung cancer cells (16). Cryptotanshinone can regulate mitochondrial function (17). As a STAT3 inhibitor, cryptotanshinone was demonstrated to inhibit the proliferation of lung cancer cells in the present study. Colivelin is a neuroprotective peptide and activator of STAT3 that suppresses neuronal death by activating STAT3 in vitro (18). The current study identified that even following activation of STAT3 with colivelin, cryptotanshinone could inhibit cancer cell growth and colony formation, and promote cancer cell apoptosis. This suggests that cryptotanshinone may serve a role independent of the STAT3 pathway.

miRNAs are small non-coding RNA molecules that are 22 nucleotides long, which exhibit functions in RNA silencing and post-transcriptional regulation of gene expression by targeting mRNAs. The human genome encodes $>1,000$ miRNAs in many cell types, which target $>60 \%$ of all genes (19). The current study investigated the effects of cryptotanshinone on a number of miRNAs. miRNA expression analysis was performed following $6 \mathrm{~h}$ of treatment, while protein expression analysis was performed following $24 \mathrm{~h}$ of treatment as alterations in miRNA expression levels have been reported to occur at a faster rate compared with alterations in protein expression levels (20). It was identified that the expression levels of the following miRNAs were significantly altered following treatment with cryptotanshinone: miR-30d-5p, miR-126-3p, miR-133a, miR-338-3p, miR-451a, miR-21-5p, miR-96-5p, miR-182-5p and miR-205-5p. Among these miRNAs, the expression levels of miR-133a were the most significantly affected following treatment with cryptotanshinone.

MMPs, also termed matrixins, are calcium-dependent zinc-containing endopeptidases (21). MMPs are capable of degrading numerous extracellular matrix proteins and are involved in the cleavage of cell surface receptors, the release of apoptotic ligands and chemokine/cytokine inactivation (22). In addition, MMPs serve key roles in cell proliferation, migration, differentiation, angiogenesis, apoptosis and host defense $(23,24)$. The present study identified that the expression levels of MMP14 were significantly downregulated following treatment with cryptotanshinone. Conversely, the expression levels of other type-I transmembrane proteins, MMP15, MMP16 and MMP24, were not significantly affected by cryptotanshinone treatment. Therefore, it can be suggested that MMP14 is a potential target of miR-133a. MMP14 can interact with TIMP2, an inhibitor of MMPs that is critical for the maintenance of tissue homeostasis $(25,26)$. The current study investigated the expression of TIMP 2 following treatment with cryptotanshinone, however, no significant change in expression level was detected compared with untreated control cells. This suggests that miR-133a, instead of TIMP2, regulates MMP14. A previous study has also demonstrated that miR-133a may target and regulate the expression of MMP14 (27).

The tumor microenvironment is important in the process of cancer metastasis and can be regulated by many natural products of herbs (28). Therefore, in future studies it may be beneficial to investigate the tumor microenvironment following treatment with cryptotanshinone. Furthermore, the metabolism of numerous chemicals is dependent on cytochrome P450, therefore, it may be beneficial to study the effects of cryptotanshinone on cytochrome $\mathrm{P} 450$ reductase, which serves a key role in cellular proliferation, and astrocytosis in particular (29).

Cancer metastasis is the leading cause of cancer-associated mortality, and is defined as the spread of cancer cells to neighboring tissues and organs beyond the initial tumor location (30). Cell invasion is the first and most important step of metastasis, which is a complex process that involves invasive cancer cells infiltrating nearby tissues and disseminating to secondary sites through the extracellular matrix $(31,32)$. To the best of our knowledge, it remains unclear whether miR-133a directly induces a decrease in MMP14 expression or indirectly regulates this process via other factors. Providing that miR-133 is upregulated during this process, it may be beneficial to use an miR-133 inhibitor in the presence or absence of cryptotanshinone to determine the mechanism of regulation in future studies.

In conclusion, the present study identified that following treatment with cryptotanshinone, the metastatic capabilities of lung cancer cells were significantly inhibited. This indicates that cryptotanshinone may serve as a potential therapeutic agent for the treatment of lung cancer. Further research regarding this topic is currently being performed in our lab.

\section{Acknowledgements}

Not applicable.

\section{Funding}

This study was supported by Science and Technology Major Project of Gansu Province (grant no. 143FKDH002).

\section{Availability of data and materials}

The datasets used and/or analyzed during the current study are available from the corresponding author on reasonable request.

\section{Authors' contributions}

YSZ made substantial contributions to the design of the study. HW, YSZ, YGZ and WL performed the experiments. YGZ and JW performed the data analysis. HW and YSZ wrote the manuscript. All authors read and approved the final manuscript.

\section{Ethics approval and consent to participate}

Not applicable.

\section{Patient consent for publication}

Not applicable. 


\section{Competing interests}

The authors declare that they have no competing interests.

\section{References}

1. Korrodi-Gregório L, Soto-Cerrato V, Vitorino R, Fardilha M and Pérez-Tomás R: From Proteomic Analysis to Potential Therapeutic Targets: Functional Profile of Two Lung Cancer Cell Lines, A549 and SW900, Widely Studied in Pre-Clinical Research. PLoS One 11: e0165973, 2016.

2. Bray F, Ferlay J, Soerjomataram I, Siegel RL, Torre LA and Jemal A: Global cancer statistics 2018: GLOBOCAN estimates of incidence and mortality worldwide for 36 cancers in 185 countries. CA Cancer J Clin 68: 394-424, 2018.

3. Maj E, Filip-Psurska B, Milczarek M, Psurski M, Kutner A and Wietrzyk J: Vitamin D derivatives potentiate the anticancer and anti-angiogenic activity of tyrosine kinase inhibitors in combination with cytostatic drugs in an A549 non-small cell lung cancer model. Int J Oncol 52: 337-366, 2018.

4. Chen W, Lu Y, Chen G and Huang S: Molecular evidence of cryptotanshinone for treatment and prevention of human cancer. Anticancer Agents Med Chem 13: 979-987, 2013.

5. Chen L, Wang HJ, Xie W, Yao Y, Zhang YS and Wang H: Cryptotanshinone inhibits lung tumorigenesis and induces apoptosis in cancer cells in vitro and in vivo. Mol Med Rep 9: 2447-2452, 2014

6. Lu L, Zhang S, Li C, Zhou C, Li D, Liu P, Huang M and Shen X: Cryptotanshinone inhibits human glioma cell proliferation in vitro and in vivo through SHP-2-dependent inhibition of STAT3 activation. Cell Death Dis 8: e2767, 2017.

7. Shen L, Zhang G, Lou Z, Xu G and Zhang G: Cryptotanshinone enhances the effect of Arsenic trioxide in treating liver cancer cell by inducing apoptosis through downregulating phosphorylatedSTAT3 in vitro and in vivo. BMC Complement Altern Med 17: 106, 2017.

8. Macfarlane LA and Murphy PR: MicroRNA: Biogenesis, Function and Role in Cancer. Curr Genomics 11: 537-561, 2010.

9. Pratap P, Raza ST, Abbas S and Mahdi F: MicroRNA-associated carcinogenesis in lung carcinoma. J Cancer Res Ther 14: 249-254, 2018.

10. Castro D, Moreira M, Gouveia AM, Pozza DH and De Mello RA: MicroRNAs in lung cancer. Oncotarget 8: 81679-81685, 2017.

11. Osada $\mathrm{H}$ and Takahashi T: let-7 and miR-17-92: small-sized major players in lung cancer development. Cancer Sci 102: 9-17, 2011.

12. Kim YH, Lee WK, Lee EB, Son JW, Kim DS and Park JY: Combined Effect of Metastasis-Related MicroRNA, miR-34 and miR-124 Family, Methylation on Prognosis of Non-Small-Cell Lung Cancer. Clin Lung Cancer 18: e13-e20, 2017.

13. Zhou Y, Wu D, Tao J, Qu P, Zhou Z and Hou J: MicroRNA-133 inhibits cell proliferation, migration and invasion by targeting epidermal growth factor receptor and its downstream effector proteins in bladder cancer. Scand J Urol 47: 423-432, 2013.

14. Guttilla IK and White BA: Coordinate regulation of FOXO1 by miR-27a, miR-96, and miR-182 in breast cancer cells. J Biol Chem 284: 23204-23216, 2009.

15. Ortmann RA, Cheng T, Visconti R, Frucht DM and O'Shea JJ: Janus kinases and signal transducers and activators of transcription: Their roles in cytokine signaling, development and immunoregulation. Arthritis Res 2: 16-32, 2000.
16. Pastuszak-Lewandoska D, Domańska-Senderowska D, Kordiak J, Antczak A, Czarnecka KH, Migdalska-Sęk M, Nawrot E, Kiszałkiewicz JM and Brzeziańska-Lasota E: Immunoexpression analysis of selected JAK/STAT pathway molecules in patients with non- small-cell lung cancer. Pol Arch Intern Med 127: 758-764, 2017.

17. Zhang Y, Chen L, Li F, Wang H, Yao Y, Shu J and Ying MZ: Cryptotanshinone protects against adriamycin-induced mitochondrial dysfunction in cardiomyocytes. Pharm Biol 54: 237-242, 2016.

18. Chiba T, Nishimoto I, Aiso S and Matsuoka M: Neuroprotection against neurodegenerative diseases: Development of a novel hybrid neuroprotective peptide Colivelin. Mol Neurobiol 35: 55-84, 2007.

19. Wu W: MicroRNA, Noise, and Gene Expression Regulation. Methods Mol Biol 1699: 91-96, 2018.

20. Stankevicius V, Kuodyte K, Schveigert D, Bulotiene D, Paulauskas T, Daniunaite K and Suziedelis K: Gene and miRNA expression profiles of mouse Lewis lung carcinoma LLC1 cells following single or fractionated dose irradiation. Oncol Lett 13: 4190-4200, 2017.

21. Tallant C, Marrero A and Gomis-Rüth FX: Matrix metalloproteinases: Fold and function of their catalytic domains. Biochim Biophys Acta 1803: 20-28, 2010.

22. Li S, Lu J, Chen Y, Xiong N, Li L, Zhang J, Yang H, Wu C, Zeng $\mathrm{H}$ and Liu Y: MCP-1-induced ERK/GSK-3 $\beta /$ Snail signaling facilitates the epithelial-mesenchymal transition and promotes the migration of MCF-7 human breast carcinoma cells. Cell Mol Immunol 14: 621-630, 2017.

23. Jabłońska-Trypuć A, Matejczyk M and Rosochacki S: Matrix metalloproteinases (MMPs), the main extracellular matrix (ECM) enzymes in collagen degradation, as a target for anticancer drugs. J Enzyme Inhib Med Chem 31 (Supp 1): 177-183, 2016.

24. Chen Q, Jin M, Yang F, Zhu J, Xiao Q and Zhang L: Matrix metalloproteinases: Inflammatory regulators of cell behaviors in vascular formation and remodeling. Mediators Inflamm 2013: 928315, 2013.

25. Xu J, Liu XJ, Li L, Zhang SH, Li Y, Gao RJ and Zhen YS: An engineered TIMP2-based and enediyne-integrated fusion protein for targeting MMP-14 shows potent antitumor efficacy. Oncotarget 6: 26322-26334, 2015.

26. Prideaux M, Staines KA, Jones ER, Riley GP, Pitsillides AA and Farquharson C: MMP and TIMP temporal gene expression during osteocytogenesis. Gene Expr Patterns 18: 29-36, 2015.

27. Xu M and Wang YZ: miR 133a suppresses cell proliferation, migration and invasion in human lung cancer by targeting MMP 14. Oncol Rep 30: 1398-1404, 2013.

28. Zhang Y, Yao Y, Wang H, Guo Y, Zhang H and Chen L: Effects of salidroside on glioma formation and growth inhibition together with improvement of tumor microenvironment. Chin J Cancer Res 25: 520-526, 2013.

29. Yao Y, Liu S, Wang Y, Yuan W, Ding X, Cheng T, Shen Q and $\mathrm{Gu}$ J: Suppression of cytochrome P450 reductase expression promotes astrocytosis in subventricular zone of adult mice. Neurosci Lett 548: 84-89, 2013.

30. Guan X: Cancer metastases: Challenges and opportunities. Acta Pharm Sin B 5: 402-418, 2015.

31. Perlikos F, Harrington KJ and Syrigos KN: Key molecular mechanisms in lung cancer invasion and metastasis: A comprehensive review. Crit Rev Oncol Hematol 87: 1-11, 2013.

32. Pawelek JM and Chakraborty AK: The cancer cell - leukocyte fusion theory of metastasis. Adv Cancer Res 101: 397-444, 2008. 